\title{
FUNGI AS BIOCONTROL AGENTS IN NATURE: INTERACTION OF FUNGI ON PHYLLOPLANE OF DATURA METEL L. AND VIGNA CATJANG L.
}

\author{
SHAMIM SHAMSI ${ }^{1}$, NAJMUN NAHER ${ }^{2}$ AND ROKEYA HAQ ${ }^{3}$
}

Keywords: Fungi, biocontrol, nature, phylloplane, Datura metel, Vigna catjang

Leaf surface is an intensely competitive environment for fungi. Recently, three species of fungi were noticed on phyllaplane of Datura metel L. The fungi were Colletotrichum sp., Pseudocercospora sp .and Trichoderma viride Pers. All the three fungi along with Trichothecium roseum Link were found on Vigna catjang L. Interaction among these fungi on phylloplane of their respective plants are presented in this paper.

Psuedocercospora sp., Colletotrichum sp, Trichoderma viride, and Trichothecium roseum belong to the class Deuteromycetes. Pseudocercospora sp. causes indistinct leaf spots with greenish black superficial mycelial growth mostly on ventral surface of leaves. Colletotrichum sp. is a facultative parasite, responsible for anthracnose of various economically important plants. Trichoderma viride is a well known biocontrol agent throughout the world. T. roseum is a saprophytic fungus, sometimes found as laboratory contaminants. It is also an established biocontrol agent. Phylloplane mycoflora on Vigna sinensis L, and their interaction was described by Shamsi and Naher (2010).

The biological control of plant disease has recently gaining appreciable importance to Plant Pathologists. Intensive research has been done in this field to avoid the hazardous impact of pesticides and agro-chemicals on ecosystem. The biological agents, the mycoparasites have also attained a significant position. It has been suggested that efforts should be made to investigate the biological control of plant disease through parasitism and predation.

Present study was made to evaluate the antagonistic activities of $T$. viride and T. roseum against Pseudocercospora sp. and Colletotrichum sp. on leaves of $D$. metel and V.catjang.

Samples of D. metel were collected from Botanic Garden Curzon Hall Campus, Dhaka University, Dhaka. Infected leaf lets of V. catjang were collected from New D.O.H.S Mohakhali and Sobhanbag, Dhaka. In total twelve samples were examined for each plant. Freshly collected samples were used for microscopic observation of fungal structures. The fungi associated with $D$. metel and V. catjang were isolated following "Tissue Planting" and "Blotter"

${ }^{1}$ Department of Botany, University of Dhaka (DU), Dhaka-1000, ${ }^{2}$ Department of Botany, Life and Earth Science Group, National University, Gazipur-1704, Bangladesh, ${ }^{3} \mathrm{MS}$ in Botany, Department of Botany, DU, Dhaka, Bangladesh. 
method for further investigations. Organisms from infected area were mounted on slides with lactophenol and cotton blue. Spore colour was examined on slides with water as mounting fluid. Digital and Photomicrographs were made for each samples. Identification of the isolates were determined following the standard literatures (Ellis 1971, 1976 and Sutton, 1980). Samples were deposited in the Mycological Herbarium of Botany Department, University of Dhaka, Bangladesh.

All the isolated fungi were tested for their pathogenic potentiality following "Detached leaf technique" (modified). Moist chamber was prepared by placing small cotton bar at the corner of Petri plate and autoclaved. Six treatments with three replications for each fungi was used as follows: control for unpricked and pricked leaves; dorsally inoculated unpricked and pricked leaves; and ventrally inoculated unpricked and pricked leaves.

During the $3^{\text {rd }}$ week of October, leaves of Datura metel were attacked by Colletotrichum sp. causing anthracnose symptom, shortly the symptoms were covered by Pseudocercospora sp. causing indistinct spots with greenish black effuse fungal colony. Numerous spots covered the entire leaves. From $27^{\text {th }}$ October Trichoderma viride started to colonize around Pseudocercospora colonies and within 7 days it destroyed conidiophores and conidia of the fungus. Infectcted leaves became yellowish, dried and dropped earlier. At late stage plants completely died (Plate 1. A -J). Colletotrichum sp. and T. viride were isolated on PDA medium.

From 5 to 8 August 2010, typical anthracnose symptom was noticed on leaflets of $V$. catjang. Within seven days greenish black colonies of Pseudocercospora were visible on necrotic lesions and on fresh leaflets of $V$. catjang. After three to four days white Trichoderma colony covered the colonies of Pseudocercospora sp. After 3 to 4 days, entire leaflets were covered by white spore dust of T. roseum. The entire plants were affected and dried (Plate $2 \mathrm{~A}-\mathrm{H}$ ).

Present studies showed that Pseudocercospora sp. suppressed the growth of Colletotrichum sp. and Pseudocercospora itself was suppressed by Trichoderma viride. At the last stage $T$. viride was suppressed by $T$. roseum. It is an excellent example of biocontrol in nature.

In total, six fungi were found associated with phylloplane of $V$. catjang. The isolated fungi were Aspergillus sp. with perfect stage, Colletotrichum sp., Curvularia sp., Pseudocercospora sp., Trichoderma viride and Trichothecium roseum (Plate $3 \mathrm{~A}-\mathrm{H}$ ). Colletotrichum sp. was found to be pathogenic to $\mathrm{V}$. catjang. 

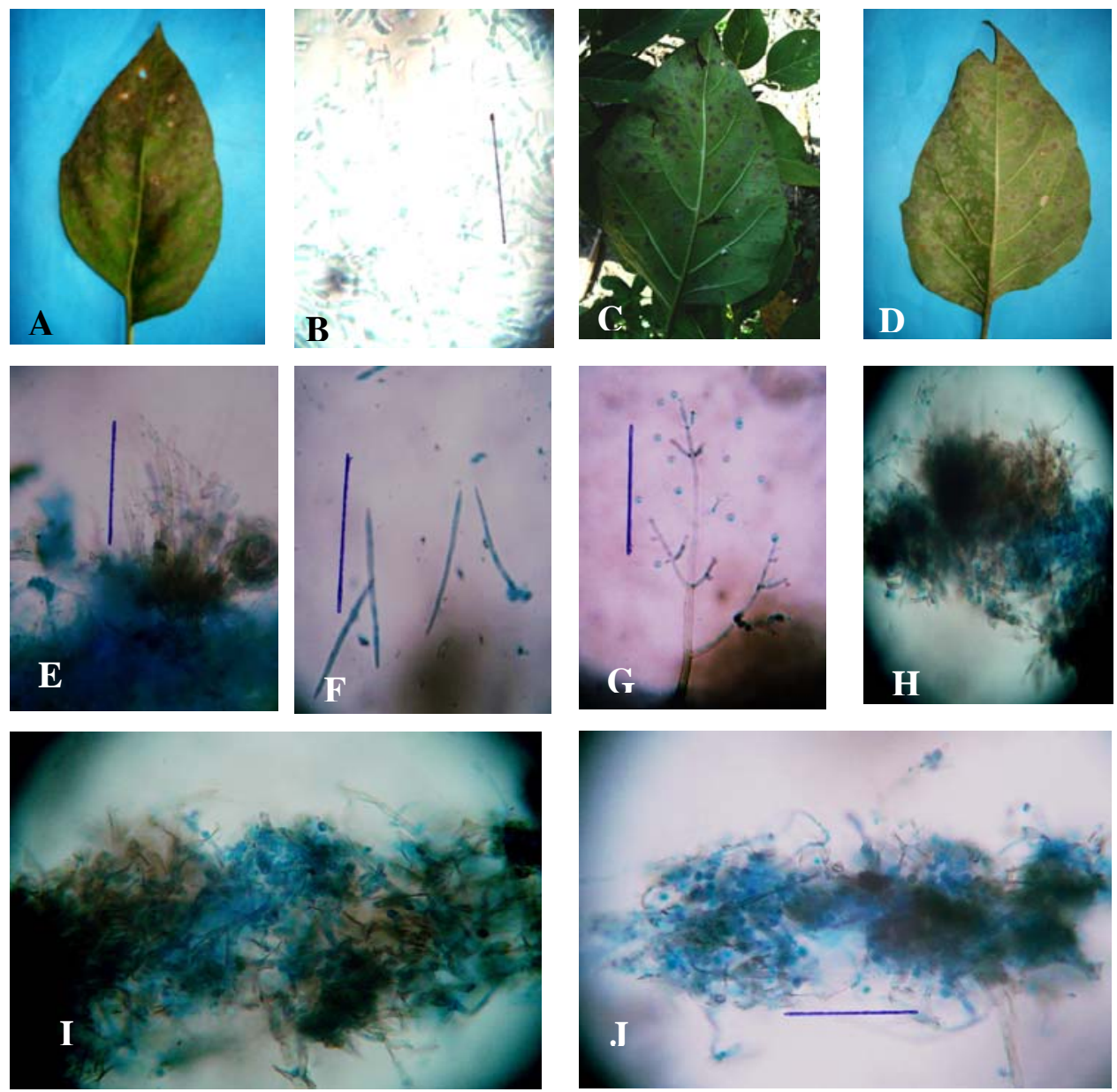

Plate 1. Photograph showing:
A. Anthracnose symptom on leaf of Datura matel .
B. Colletotrichum sp.
C. Pseudocercospora leaf spot of Datura matel
D. Leaf spot suppressed by colonies of Trichoderma viride
E - F. Conidiophore and conidia of Pseudocercospora sp.
G. Conidiophore and conidia of Trichoderma viride and

H- J. Conidiophore and conidia of Pseudocercospora sp. suppressed by

Trichoderma viride. $(\mathrm{Bar}=50 \mu \mathrm{m})$ 

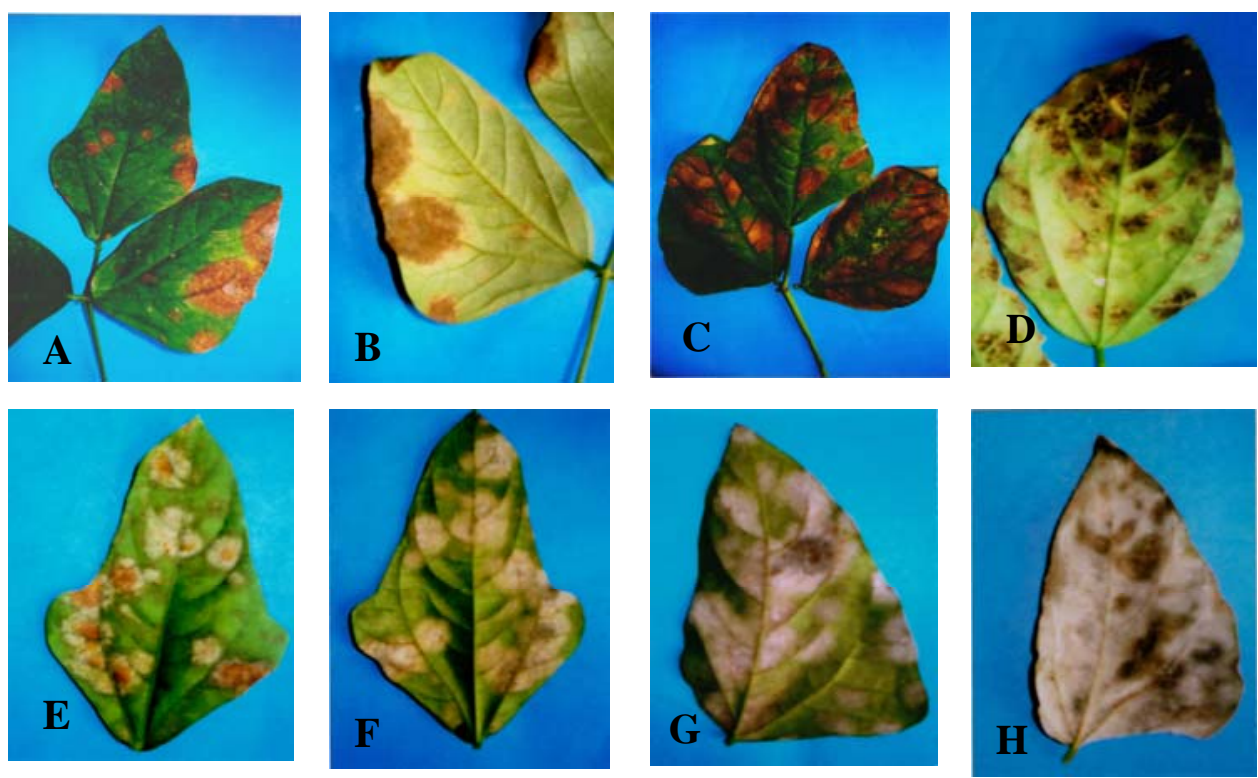

Plate 2. Photograph showing

A - B. Anthracnose symptom on Vigna catjang leaf lets (dorsal and ventral view).

C - D. Pseudocercospora leaf spot of V. catjang dorsal and ventral side of the leaflets

E - F. Trichoderma colony suppressing Pseudocercospora colony (Initial stage)

G. Pseudocercospora colony completely suppressed by Trichoderma colony and

H. Trichoderma colony gradually suppressing by Trichothaecium colony 

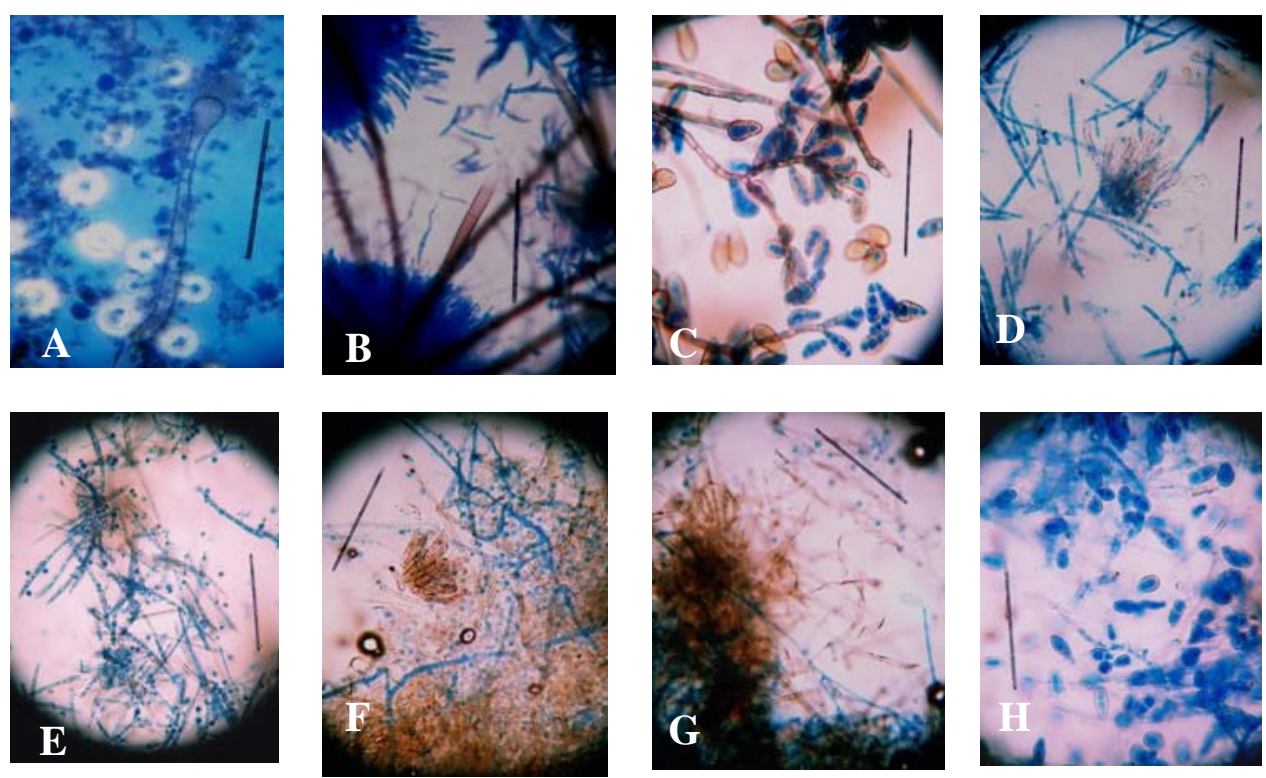

Plate 3. Photomicrographs showing

A. Aspergillus sp. and its perfect stage

B. Acervulas seti and conidia of Colletotrichum sp.

C. Conidia and conidiophore of Curvularia sp.

D. Conidia and conidiophore of Pseudocercospora sp.

E. Pseudocercospora sp. suppressing by Trichoderma viride.

F- G. Trichoderma viride completely suppressed conidia and conidiophore of

Pseudocercospora sp. and initial stage of Trichothecium roseum and

H. Trichoderma viride replaced by Trichothecium roseum. (Bars $=50 \mu \mathrm{m})$.

This investigation indicates that Trichoderma viride and Trichotheceum roseum are playing significant role in nature as biocontrol agents. This study is an excellent examples of interaction among the fungi in nature.

\section{References}

Ellis MB 1971. Dematiaceous Hyphomycetes. The commonwealth Mycological Institute, England, pp. 608.

Ellis MB 1976. More Dematiaceous Hyphomycetes. The Commonwealth Mycological Institute, England, pp. 507

Shamsi, S. and N. Naher. 2010. Hyperparasitic fungus Tuberculina persicina (Ditm. Ex Fr.) Sacc. as biocontrol agent for rusts. Dhaka Univ. J. Biol. Sci. 19(1): 203-206.

Sutton BC 1980. The Coelomycetes. Fungi Imperfect with Pycnidia Acervuli and Stroma, Commonwealth Mycological institute, Kew Surrey, England, pp. 696. 